\title{
Detrusor Action in Children with Myelomeningocele
}

\author{
D. G. W. COOPER * \\ From Department of Surgery, Queen Mary's Hospital for Children, Carshalton, Surrey
}

\begin{abstract}
About 3000 children a year are born in the United Kingdom with myelomeningocele (Eckstein and Macnab, 1966). Up to the present time attention has been focused on early closure of the back lesion, adequate and efficient drainage of the hydrocephalus, and management of the orthopaedic problems. It is now to be expected in our present series that $75 \%$ of these children will be of normal intelligence, and most of them will walk, with the aid of calipers if necessary. Their major handicap as they approach school age will be their incontinence. In many instances this will prevent them attending normal schools.
\end{abstract}

Figures concerning continence in these children vary widely. In a recent review of older patients Eckstein (1968) found that $30 \%$ were continent. $\mathrm{He}$ attributes the high continence rate in this series to the fact that these children, treated largely before the impact of modern treatment, represent a highly selected group. Carlson (1966) states that, in his series, $40 \%$ of the boys and $20 \%$ of the girls ultimately achieve some form of urinary control. However, the experience of most workers in this country is that the majority will be incontinent. In a review of 415 cases born in the years 1958-65 we found a continence rate of only $13 \%$ (Cooper, 1967), and in a more recent review of a further 112 cases we found this to be only $11 \%$.

We have examined in greater detail a group of 142 children with myelomeningocele, of varying ages from 10 days to 13 years, with a view to establishing the state of continence, the results of intensive toilet training, and the future prognosis for these children under the age of 2 years at the time of the examination.

The only method of studying bladder action in these children is by means of cystometric techniques. Cystometry has grown from a study of detrusor contraction to an elaborate physiological study of bladder function by the inclusion of uroflometry, pelvic floor studies, intra-abdominal

Received January 31, 1968.

* Present address: Box 1727, Williams Lake, B.C., Canada. pressures, and hydrodynamic analysis. A complete study of bladder function includes observation of the bladder cycle throughout both filling and emptying. This is best achieved by direct cystometry and uroflometry (Boyarsky et al., 1966). The introduction of suprapubic puncture techniques (Murphy and Schoenberg, 1960), and the development of sensitive electronic pressure transducers and recorders has made this possible.

\section{Method}

Bladder pressures are recorded through a fine nylon intravenous cannula (F.G. 2) which is introduced into the bladder suprapubically through an 18-gauge lumbar puncture needle. The needle is then withdrawn, leaving the cannula in the bladder. A second cannula is inserted in a similar manner, and will be used to expedite bladder filling. This is achieved by means of a pressurized bottle of normal saline $(250 \mathrm{~mm}$. $\mathrm{Hg}$ ). Pressurization is necessary because of the very fine diameter of the tubing, and enables a filling rate of 2 ml. per minute to be achieved.

Intra-abdominal pressure can be accurately recorded by means of a high rectal Foley catheter. The inflated balloon occludes the rectum, and fluid may then be run in to form a fluid-filled recording chamber in the upper rectum. Changes due to bowel activity are quite distinctive and easily recognized (Fig. 1). Adequate bowel preparation to ensure freedom from faeces is desirable.

Pelvic floor activity is recorded by the contractions of the external anal sphincter which is part of the levator ani. A special obturator has been designed by us with a fluid-filled bag around its waist (Fig. 2), which is gripped by the anal sphincter, and contraction of this muscle will be recorded as a rise of pressure in this chamber.

All systems are fluid filled and connected to Sanborn physiological pressure transducers, and through these to Sanborn 350.3000 pre-amplifiers and a Sanborn 4-channel direct writing recorder.

We measured flow by means of a U-tube with a receiving and a recording limb. A float and a displacement transducer (Linearsyn 585 DT-1000) record the rate of rise of fluid in the U-tube, and this is recorded via a $350.1100 \mathrm{C}$ pre-amplifier and the fourth channel of the Sanborn recorder. In practice we have found 


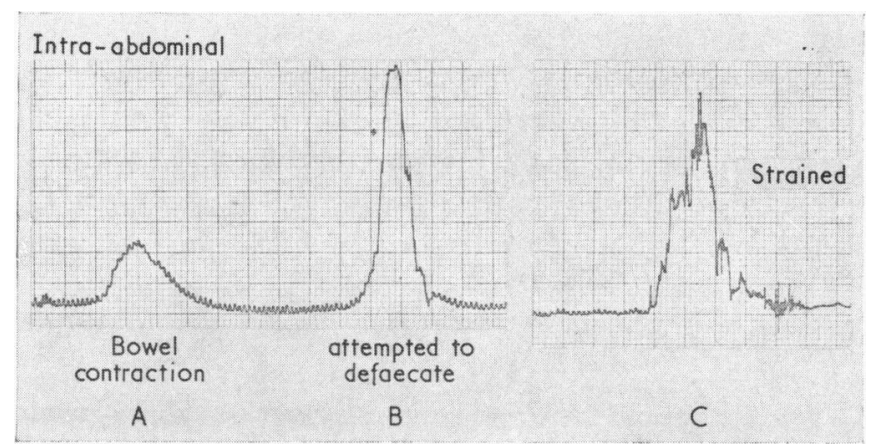

FIG. 1.-(a) Perseverance of respiratory swing during contraction of bowel (probably sigmoid colon). (b) Strong rectal contraction in an attempt to defaecate. No straining took place. (c) Distinct straining efforts, no respiratory pressure waves seen.

that visual observation of the stream is usually more practical. Many children with denervated bladders have such low flow rates that they are not readily recordable with any accuracy. Older or more normal children present no difficulty. The start of voiding can be recorded by utilizing the time marker as a fifth channel, and this gives a precise timing device to compensate for the slight lag in the flow measurement.

\section{Results}

A bladder which is essentially normal does not contract reflexly in response to perineal, rectal, or abdominal stimulation. There are no contractions

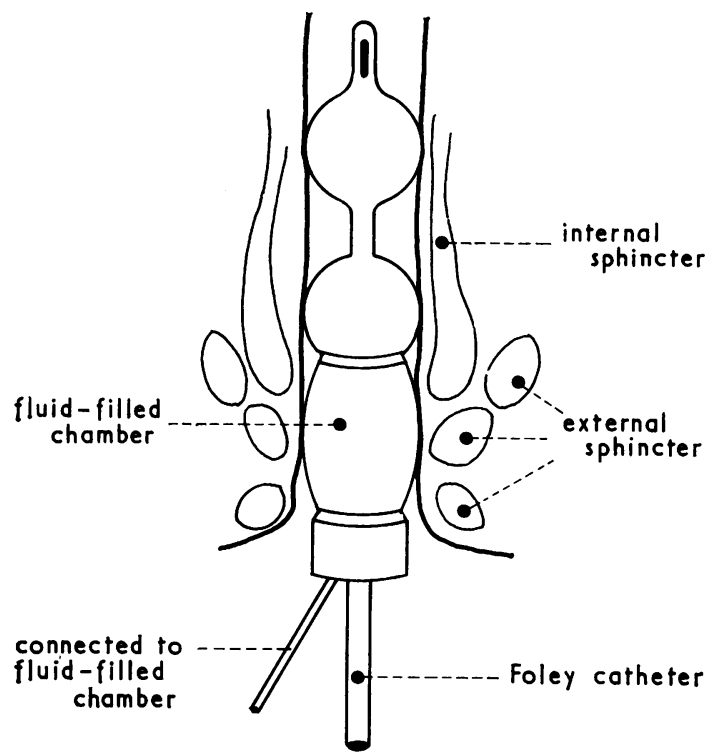

FIG. 2.-Anal obturator for measuring intra-abdominal pressure and pelvic floor contraction. during slow filling, and there is little increase in intravesical pressure until a single, well coordinated, sustained, and effective detrusor contraction produces voiding (Fig. 3 ).

On the other hand, a bladder that is totally denervated, or decentralized, will show only low level rhythmic contractions, due to the auto-rhythmicity of the detrusor muscle (Fig. 4). There will be no response to perineal, rectal, or abdominal stimulation, and there are no spontaneous detrusor contractions.

A bladder which is essentially reflex in type will contract with varying degrees of effectiveness on stimulation of either the perineum, rectum, or abdomen, depending on the state of the afferent reflex arc. The posterior roots are often involved in the lesion, and suffer varying amounts of damage. Reflex bladder contractions, however, are poorly sustained and co-ordinated, and emptying is nearly always inadequate (Fig. 5).

In all, 142 children, varying in age from 10 days to 13 years, have been examined. Of these, 54 (38\%) show detrusor activity which is essentially normal in pattern (Table I). Only 36 of these were over the age of 2 years and could be assessed for possible continence. Their present status is shown in Table II. On first examination only 8 $(22 \%)$ of these children were continent, but after showing normal detrusor activity a further 12 children were immediately toilet trained, bringing the total number of those at present continent in this group to $55 \%$. Of 9 children still undergoing toilet training, 2 have extensive sensory loss as their main neurological deficit. A less extensive sensory loss is frequently present in children with apparently normal detrusor action. Only 4 children in this group are considered to be not worth training. Of these, 2 are very retarded, and 2 are completely 


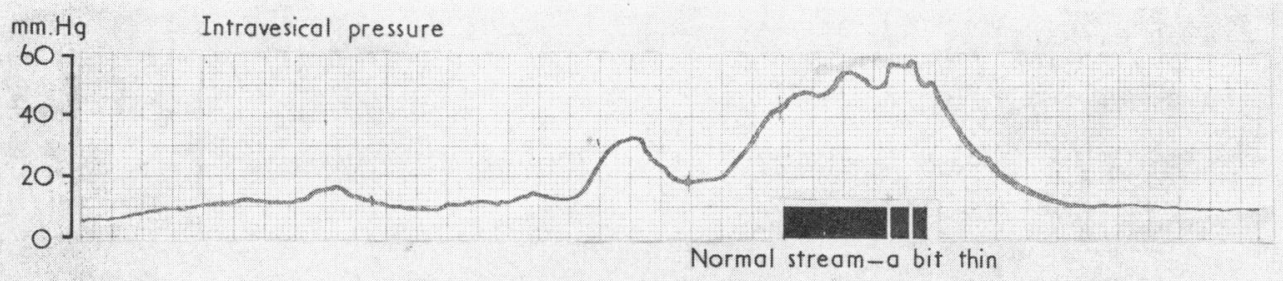

Pelvic floor

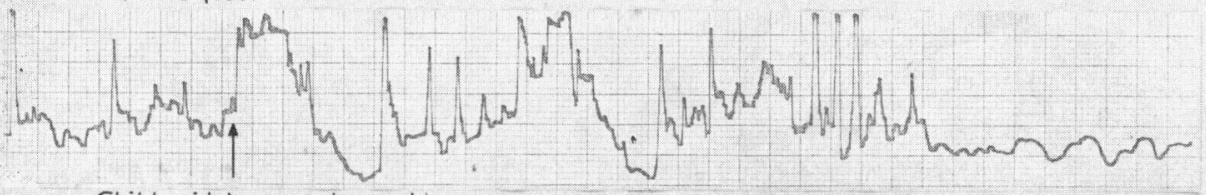

Child said he wanted to void
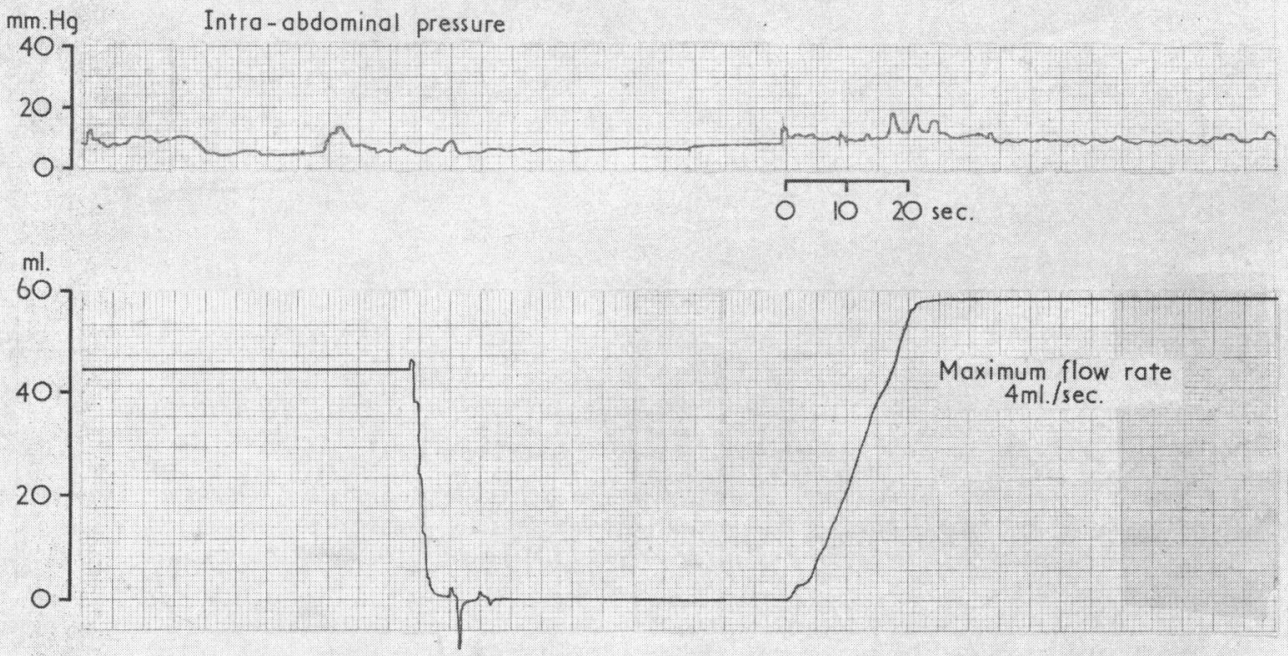

FIG. 3.-A 7-year-old boy with a lumbar myelomeningocele and weakness in the legs below the level of L3. Essentially normal detrusor action with normal sensation. Child continent.

incontinent after transurethral resection of the bladder neck.

The children with normal detrusor action were compared as a group with the remaining children, to see if division into this group was of any clinical

TABLE I

Constitution of Series

\begin{tabular}{c|c|c}
\hline Age (yr.) & $\begin{array}{c}\text { Normal Bladder } \\
\text { Action }\end{array}$ & Remainder \\
\hline$>2$ & 36 & 61 \\
$<2$ & 18 & 27 \\
\hline Total & 54 & 88 \\
\hline
\end{tabular}

significance. The incidence of continence, urinary tract infection, upper urinary tract dilatation, and

TABLE II

Details of Group with Normal Detrusor Action

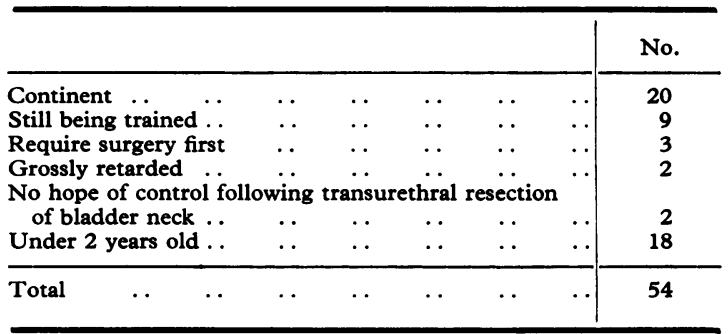



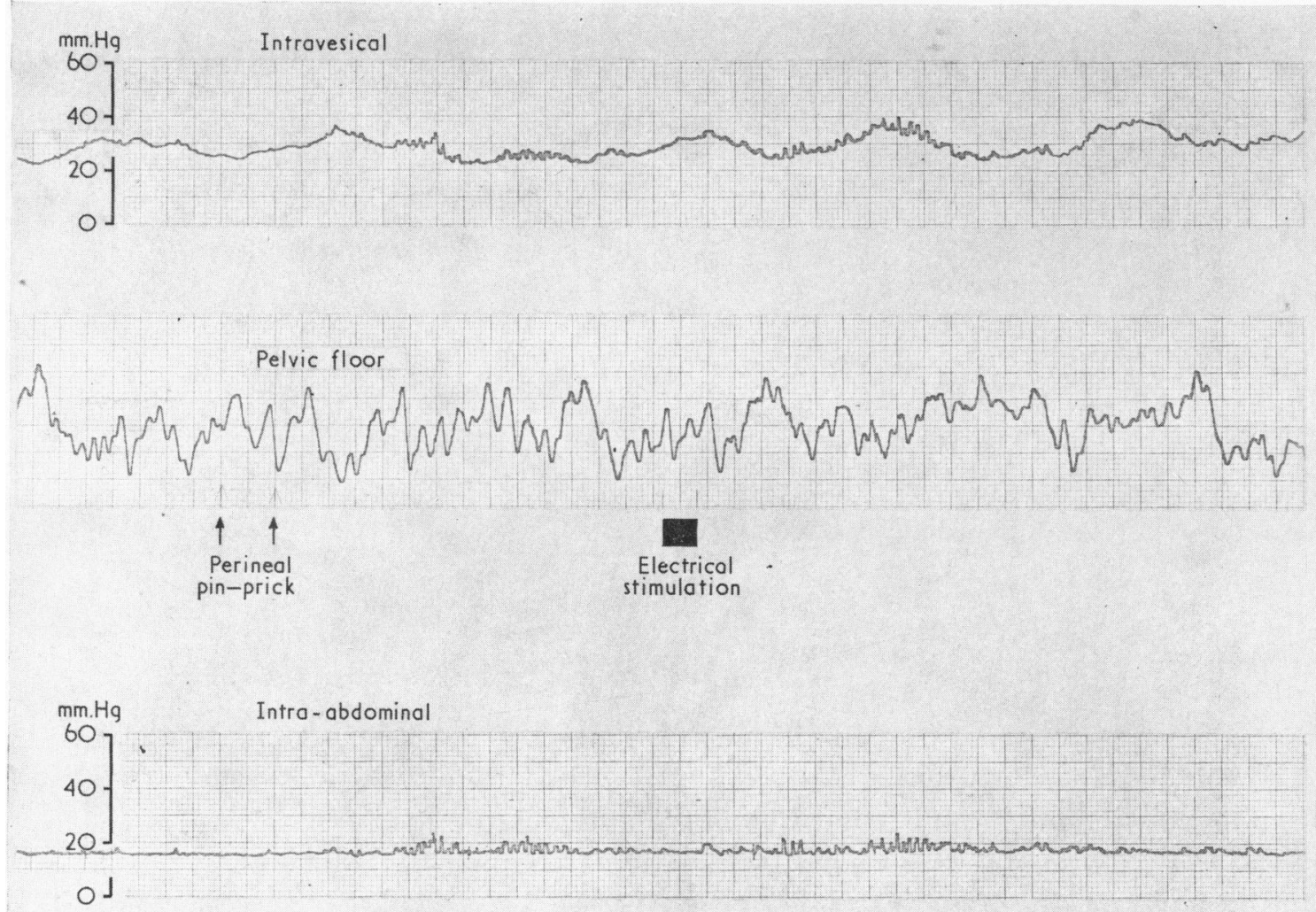

FIG. 4. A 9-year-old boy with a lumbar myelomeningocele and treated hydrocephalus. Complete paralysis below the level of L2. Completely denervated bladder showing autorhythmicity, and pelvic floor showing smooth muscle activity only, which fails to respond to either perineal pin-prick or electrical stimulation.

raised intravesical pressures can be seen from Table III. Children with essentially normal detrusor action, even when sensory loss or motor weakness are present, have a much greater chance of achieving continence than those with other forms of neuropathic bladder. It can be seen that dilatation of the urinary tract is much less frequent in those with normal bladder action. Urinary tract infection is

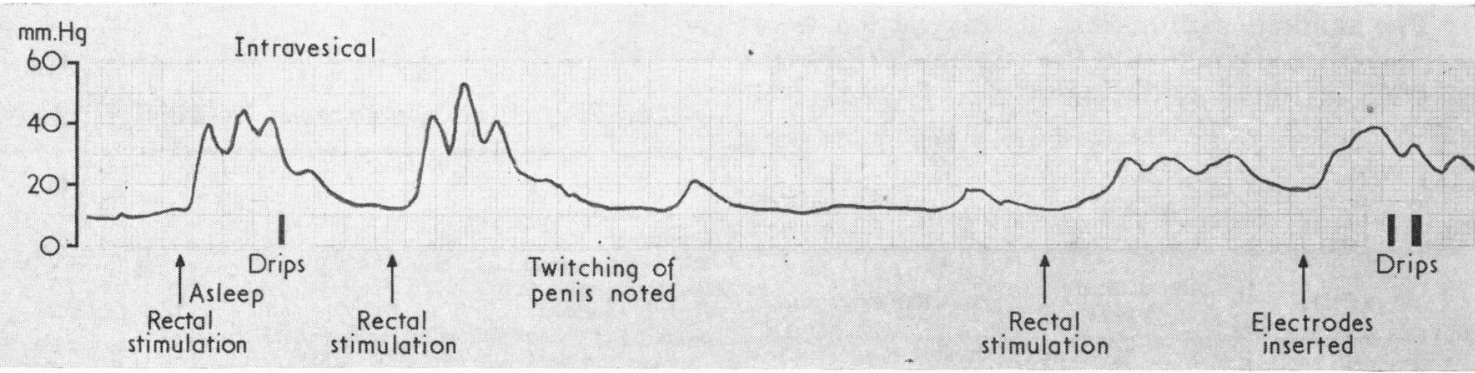

FIG. 5.-A 1-month-old boy with a lumbar myelomeningocele and treated hydrocephalus. Evidence of denervation below L1. Reflex type of detrusor activity with brisk response to rectal stimulation and the insertion of perineal electrodes. These detrusor contractions are ineffective in emptying the bladder. 
TABLE III

Relative Incidence of Continence, Infection, Upper Urinary Tract Dilatation, and Raised Intravesical Pressure in Children with Normal Detrusor Action, Compared with Remainder of Series

\begin{tabular}{|c|c|c|c|}
\hline & & $\begin{array}{l}\% \text { With } \\
\text { Normal } \\
\text { Detrusor } \\
\text { Action (54) }\end{array}$ & $\begin{array}{c}\% \text { of } \\
\text { Remainder } \\
(88)\end{array}$ \\
\hline $\begin{array}{lll}\text { Continence } & \ldots & \ldots \\
\text { Infection } \ldots & \ldots & \ldots \\
\text { Dilatation .. } & \ldots & \ldots \\
\text { Raised intravesical pressure }\end{array}$ & $\begin{array}{l}\cdots \\
\cdots \\
\cdots \\
\cdots\end{array}$ & $\begin{array}{l}55 \\
37 \\
20 \\
18\end{array}$ & $\begin{array}{l}21 \\
46 \\
45 \\
17\end{array}$ \\
\hline
\end{tabular}

also less frequent in this group, but there is no difference in the incidence of raised intravesical pressures. These figures strongly suggest that factors other than raised intravesical pressure are responsible for urinary tract dilatation in many of these children.

The follow-up period is too short to compare morbidity or mortality in these different groups. 5 children have died since these studies were performed; 4 of them had reflex type bladder action and died from causes quite unrelated to their urinary tract; and the other had a normal type of bladder, but died of septicaemia after a transurethral resection for obstruction at the level of the bladder neck. We have shown elsewhere that children with decentralized bladders have the worst prognosis as regards their urinary tract (Cooper, 1968). Though they all have low intravesical pressures due to the complete paralysis of the bladder, nevertheless infection and dilatation are greatest, and urinary diversion procedures are commonest in this group.

When the incidence of normal, reflex, and decentralized action is examined relative to age (Fig. 6)

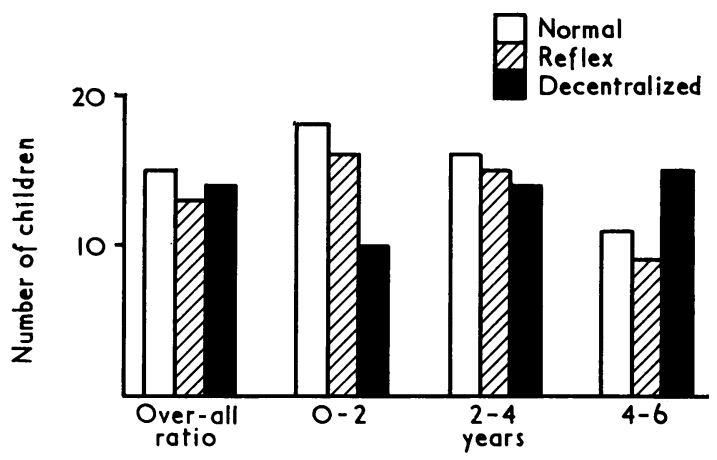

FIG. 6.-The age distribution of children with normal detrusor action compared with the remainder of the series. it will be seen that the proportion of those with innervated bladders (both normal and reflex) is greater in the children under 2 years, and falls progressively with increasing age, while the proportion of those with decentralized bladders rises. This suggests that neurological deterioration in the status of the bladders of these children may take place as they grow older. This will only be confirmed if deterioration is shown in the group under 2 years as they grow older. Neuromuscular deterioration in the lower limbs occurs in at least $20 \%$ of these children during the first year of life (unpublished observations), due either to local causes such as implantation dermoid cysts at the site of the repair, or to general causes such as meningitis and episodes of raised intracranial pressure. It is to be expected that the bladder might share in this deterioration.

\section{Discussion}

The difficulties encountered in classifying abnormal function in neurogenic bladder disease are due, in part, to a lack of understanding of various mechanisms of bladder anatomy and function. It has now been established that tonus and rhythmicity are inherent properties of smooth muscle, and are not dependent on an intact nerve supply (Bülbring, 1957; Plum, 1960; Plum and Colfelt, 1960; Sabetian, 1965). Hypertonicity and atonicity merely reflect the physical state of the bladder wall, and are unrelated to the innervation of that organ. A constantly leaking or frequently emptied bladder will become small and hypertonic. On the other hand, a bladder with poor or inadequate emptying will become large and atonic. Sensation, reflex activity, and suprasegmental control of the reflex are the features that depend on innervation, and it is these features that we have endeavoured to evaluate. This can only be achieved by a study of the type of contraction produced by the detrusor muscle. A knowledge of the capacity and appearance of the bladder reflects only its physical state at that moment.

It is only possible to monitor bladder behaviour during filling and voiding in children by means of a suprapubic puncture technique, interfering as little as possible with the normal behaviour of the bladder.

Whitaker and Johnston (1966) have shown that the presence of a urethral catheter reduces flow and raises intravesical pressures, and we have shown (Cooper, 1968) that it may act as a powerful irritant and lower the threshold of the micturition reflex to such a level that it may be impossible to 
fill the bladder. This has also been reported by Fry et al. (1966).

Using the techniques which we have described, we have found that it is possible to classify these children into 3 main types, depending, on their detrusor function: (a) Those with normal detrusor function; (b) those with a cord, upper motor neurone, or reflex type of bladder; and (c) those with completely denervated, lower motor neurone, or decentralized bladders.

We have favoured a physiological terminology (Ruch, 1960), as it is more descriptive than the clinical terms.

There is often considerable overlap between these types due to the widespread nature of the neurological lesion, but one type of detrusor action usually predominates. We have been able to show detrusor action which is basically normal in $38 \%$ of all children with myelomeningocele, and in $31 \%$ of all those children who were incontinent on first examination. In these children with relatively normal detrusor action there are varying degrees of sensory loss resulting from either dorsal root or ascending tract damage. In addition, there is often a motor weakness due to partial motor denervation. There are significant differences both in the rate of continence which may be expected in this group, and in the incidence of upper urinary tract dilatation.

\section{Conclusions}

Of all children with myelomeningocele, $38 \%$ have detrusor action which is essentially normal.

Providing that there is good cerebral function, and depending on the extent of sensory denervation, it should be possible to toilet train most of these children. $55 \%$ of the children in this series with normal detrusor action are now continent.

The incidence of upper urinary tract dilatation in children with normal detrusor action is only $20 \%$, as compared to $45 \%$ in those children with reflex or decentralized bladders, and $29 \%$ in the group as a whole. The incidence of raised intravesical pressures is similar in both groups, and it appears that paralysis and infection are important causes of upper urinary tract dilatation in many of these children.

A study of the age distribution of children with the various types of bladder activity mentioned suggests that there may be a deterioration in the neurological status of the bladder in many of these children after the first two years of life.

It is useful to classify this group of children with a good prognosis as regards continence and upper urinary tract dilatation at as early an age as possible. Further treatment and future management can then be planned accordingly.

I would like to thank Mr. H. B. Eckstein and Mr. D. $M$. Forrest for kind permission to study their cases.

This work was supported by a research grant from the South-West Metropolitan Regional Hospital Board.

\section{REFERENCES}

Boyarsky, S., Labay, P., Krugman, A., Glenn, J. F., and Newmark, T. (1966). Clinical evaluation of bladder pressure studies in urological patients by combined cystometry and uroflometry. f. Urol. (Baltimore), 95, 778.

Bülbring, E. (1957). The action of humoral transmitters on smooth muscle. Brit. med. Bull., 13, 172.

Carlson, H. E. (1966). Urologic problems in meningomyelocele. 7. Urol. (Baltimore), 95, 245.

Cooper, D. G. W. (1967). Urinary tract infection in children with myelomeningocele. Arch. Dis. Childh., 42, 521.

(1968). Brit. F. Urol. In the press.

Eckstein, H. B. (1968). Brit. F. Urol. In the press.

$\longrightarrow$, and Macnab, G. H. (1966). Myelomeningocele and hydrocephalus. The impact of modern treatment. Lancet, 1, 842.

Fry, I. K., McKinna, J. A., Simon, G., and Smart, P. J. G. (1966). Some observations on the lower urinary tract in infants with spina bifida cystica. Proc. roy. Soc. Med., 59, 420.

Murphy, J. J., and Schoenberg, H. W. (1960). Observations on intravesical pressure changes during micturition. f. Urol. (Baltimore), 84, 106.

Plum, F. (1960). Autonomous urinary bladder activity in normal man. Arch. Neurol. (Chic.), 2, 497.

—, and Colfelt, R. H. (1960). The genesis of vesical rhythmicity. ibid., 2, 487.

Ruch, T. C. (1960). Neurophysiology Vol. II. Chapter XLVIII, American Physiology Society.

Sabetian, M. (1965). The genesis of bladder tone. Brit. F. Urol., $37,424$.

Whitaker, J., and Johnston, G. S. (1966). Urinary flow rate with 2 techniques of bladder pressure measurement. Invest. Urol., 4, 235. 